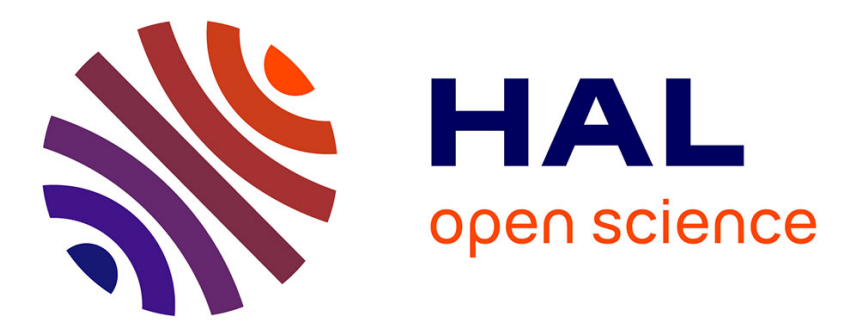

\title{
Efficacy of molecularly targeted agents given in the randomised trial SHIVA01 according to the ESMO Scale for Clinical Actionability of molecular Targets
}

A. Moreira, J. Masliah-Planchon, C. Callens, S. Vacher, C. Lecerf, M. Frelaut, E. Borcoman, N. Torossian, F. Ricci, S. Hescot, et al.

\section{To cite this version:}

A. Moreira, J. Masliah-Planchon, C. Callens, S. Vacher, C. Lecerf, et al.. Efficacy of molecularly targeted agents given in the randomised trial SHIVA01 according to the ESMO Scale for Clinical Actionability of molecular Targets. European Journal of Cancer, 2019, 121, pp.202 - 209. 10.1016/j.ejca.2019.09.001 . hal-03488907

\section{HAL Id: hal-03488907 https://hal.science/hal-03488907}

Submitted on 21 Dec 2021

HAL is a multi-disciplinary open access archive for the deposit and dissemination of scientific research documents, whether they are published or not. The documents may come from teaching and research institutions in France or abroad, or from public or private research centers.
L'archive ouverte pluridisciplinaire HAL, est destinée au dépôt et à la diffusion de documents scientifiques de niveau recherche, publiés ou non, émanant des établissements d'enseignement et de recherche français ou étrangers, des laboratoires publics ou privés.

\section{(ㄷ)(1) $\$$}

Distributed under a Creative Commons Attribution - NonCommerciall 4.0 International 
Version of Record: https:/www.sciencedirect.com/science/article/pii/S095980491930499X

Manuscript_05228a063fc232a64f134e82d004d92d

Efficacy of molecularly targeted agents given in the randomized trial SHIVA01 according to the ESMO Scale for Clinical Actionability of molecular Targets (ESCAT)

Authors: A. Moreira ${ }^{1}$, J. Masliah-Planchon ${ }^{2}$, C. Callens ${ }^{2}$, S. Vacher ${ }^{2}$, C. Lecerf ${ }^{1}$, M. Frelaut ${ }^{1}$,

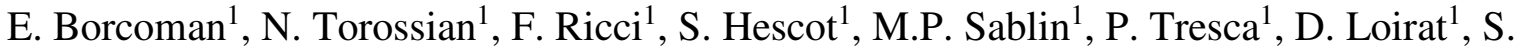
Melaabi $^{2}$, O. Trabelsi-Grati ${ }^{2}$, G. Pierron ${ }^{2}$, D. Gentien ${ }^{3}$, V. Bernard ${ }^{2}$, A. Vincent Salomon ${ }^{4}$, N.

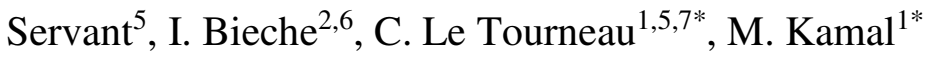

1: Department of Drug Development and Innovation (D3i), Institut Curie, Paris \& SaintCloud, France; 2: Department of Genetics, Institut Curie, PSL Research University, Paris, France; 3: Department of translational research, Institut Curie, PSL Research University, Paris, France; 4: Department of Pathology, Institut Curie, PSL Research University, Paris, France; 5: INSERM U900, Institut Curie, Mines Paris Tech, Paris, France; 6:INSERM U1016 Research Unit, Cochin Institute, Paris, France; 7: Paris-Saclay University, Paris, France

*contributed equally and should be considered co-last authors

\section{Corresponding author:}

Dr. Maud Kamal

Department of Drug Development and Innovation (D3i)

Institut Curie

26 Rue d'Ulm

75005 Paris - France

Phone : +33144324420

Email: maud.kamal@curie.fr

\section{Word Count:}

Pages $=34 ;$ Abstract $=250$ words $(\max : 250$ words $) ;$ Article $=1,838$ words $(\max : 2,500$ words); Figures $=1 ;$ Tables $=2 ;$ References $=38(\max : 40) ;$ Supplementary Figures $=1$; Supplementary Tables $=1 ;$ Supplementary Material $=1$. 


\begin{abstract}
Background SHIVA01 randomized trial compared efficacy of matched molecularly targeted therapy outside their indications based on a prespecified treatment algorithm versus conventional chemotherapy in patients with metastatic solid tumours who had failed standard of care. No statistical difference was reported between the two groups in terms of progression-free survival (PFS), challenging treatment algorithm. ESMO Scale for Clinical Actionability of molecular Targets (ESCAT) recently defined criteria to prioritize molecular alterations (MAs) to select anticancer drugs. We aimed to retrospectively evaluate the efficacy of matched molecularly targeted agents (MTAs) given in SHIVA01 according to ESCAT Tiers.
\end{abstract}

Patients and methods MAs used in SHIVA01 were retrospectively classified into ESCAT Tiers and PFS and overall survival (OS) were compared using log-rank tests.

Results Hundred and fifty-three patients were treated with matched MTAs in SHIVA01. MAs used to allocate MTAs were classified in Tiers II, IIIA, IIIB, and IVA according to ESCAT. Median PFS was 2.0 months in Tier II, 3.1 in Tier IIIA, 1.7 in Tier IIIB, and 3.2 in Tier IVA $(\mathrm{p}=0.13)$. Median OS in Tier IIIB was worse than in Tiers II, IIIA and IVA (6.3 months versus 11.7, 11.2 and 12.1, $\mathrm{p}=0.002)$.

Conclusions Most MAs used to allocate therapy in SHIVA01 were shown to improve outcome in other tumour types (Tier IIIA). Worst outcome was observed in patients treated based on another type of alteration than the one reported to improve outcome (Tier IIIB), highlighting the crucial impact of the type of the alterations beyond the gene and the signaling pathway.

Key words Molecularly targeted agents, ESMO Scale for Clinical Actionability of molecular Targets (ESCAT), actionable molecular alterations, treatment algorithms, precision medicine, SHIVA01 


\section{INTRODUCTION}

Molecularly targeted agents (MTAs) given based on specific molecular alterations (MAs) were shown to be highly effective in several cancer types, such as vemurafenib in V600E $B R A F$-mutated melanoma patients or gefitinib in EGFR-mutated non-small cell lung cancer (NSCLC) patients $[1,2]$. Several actionable MAs were identified across tumour types raising the question of comprehensive molecular profiling clinical utility to guide therapy. Precision medicine trials have been designed to assess the value of molecular profiling to allocate therapy in a histology-independent way [3-5].

SHIVA01 (NCT01771458) was the first randomized trial comparing matched MTA versus conventional therapy in patients with any kind of metastatic solid tumour refractory to standard of care [3]. SHIVA01 was negative for its primary endpoint with no statistical difference in progression-free survival (PFS) between the experimental and the control groups suggesting that SHIVA01 treatment algorithm was not able to improve patient outcomes. Improving treatment algorithms used in precision medicine trials represents a major challenge [6].

Several scales of actionability have been developed aiming at grading the levels of evidence associated with MAs [7-11], the latest one being the ESMO Scale of Actionability of molecular Targets (ESCAT) [12]. We aimed to retrospectively classify the MAs used to allocate MTAs in SHIVA01 according to ESCAT, and to evaluate MTAs efficacy accordingly.

\section{PATIENTS AND METHODS}

SHIVA01 was a proof-of-concept open-label randomized controlled phase 2 trial conducted in France [3]. MTAs used in the experimental group were drugs given outside their indications. Patients treated with MTAs following randomization or at cross-over in SHIVA01 were included in the study. 
All MAs used to allocate MTAs in SHIVA01 were classified according to ESCAT by assessing the level of evidence in the literature (Supplementary Figure S1). To this end, for each MA, we first searched for clinical trials performed with the MTA in the same tumour type that would support ESCAT levels of evidence Tiers I or II. If no data supported Tiers I or II, we then searched for clinical trials performed with the same MTA and based on the same MA but in other tumour types that would support Tier III. If no data supported ESCAT Tier III, we searched for preclinical and in silico data that would support Tier IV. MAs were classified in Tier V if no clinically meaningful benefit was reported.

PFS and overall survival (OS) according to the ESCAT levels of actionability were compared using log-rank tests (GraphPad Prism7).

\section{RESULTS}

\section{Patient population}

Hundred and one out of the 153 included patients (66\%) were females (Table 1). Median age was 57 years [range: 14-86]. MAs used to allocate therapy involved the PI3K/AKT/mTOR pathway in 77 patients $(50 \%)$, the hormone receptor pathway in 56 patients $(37 \%)$, and the Tyrosine Kinase Receptor (TKR)/RAF/MEK pathway in 20 patients (13\%). Most frequent cancer types were breast (17\%), ovarian (16\%), and colorectal (12\%) cancer.

\section{Classification of MAs according to ESCAT}

Extensive justification of MAs' classification according to ESCAT is available Supplementary Material and Table S1.

\section{PI3K/AKT/mTOR pathway}

Among 77 patients treated with everolimus, 28 patients $(36 \%)$ had a PIK3CA activating hotspot mutation, 43 patients (56\%) a PTEN inactivation, five patients (6\%) an $A K T$ 
mutation/amplification, and one patient (1\%) a STK11 inactivating mutation associated with a loss of heterozygosity (Table 2).

PIK3CA mutations, PTEN inactivations, and AKT1 mutations were shown to predict the efficacy of everolimus in HER2-positive breast cancer patients [13]. These alterations were therefore classified in Tier IIA according to ESCAT for breast cancer, and in Tier IIIA for the other cancer types. AKT amplifications were classified in Tier IIIB based on data reported with $A K T$ mutations. STK11 inactivations were classified in Tier IVA, since only preclinical data supported the use of everolimus for this MA [14].

\section{TKR/RAF/MEK pathway}

$E R B B 2$ amplifications were identified in two patients with NSCLC and urothelial cancer in SHIVA01. Given the OS benefit obtained with the combination of lapatinib and trastuzumab in $E R B B 2$-amplified breast cancer patients [15], and the lack of clinical evidence supporting the use of this combination in ERBB2-amplified NSCLC and urothelial cancer patients, ERBB2 amplifications were classified in Tier IIIA in these cancer types. ERBB2 mutations were classified in Tier IIIB for the two patients with neuroendocrine and colorectal cancers treated with this combination, based on the ERBB2 amplifications data.

KIT mutations are present in most GIST patients, explaining the high efficacy of imatinib in this patient population [16]. KIT exon 11 mutations were shown to predict the efficacy of imatinib in GIST [17], and were therefore classified in Tier IIIA in NSCLC. KIT mutations were classified in Tier IIB for melanoma, given the efficacy reported with imatinib in melanoma patients with KIT mutations/amplifications in a single-arm phase II trial [18]. KIT exon 18 mutations in ovarian cancer and KIT exon 15 mutations in hepatocellular cancer were classified in Tier IIIB, assuming the same functional impact of these mutations then for KIT exon 11 mutations. 
EGFR amplifications in oesophageal cancers were classified in Tier IIA, given the OS improvement in EGFR-amplified tumours in a retrospective analysis of a randomized trial with gefitinib [19]. Based on these results and given the lack of clinical evidence in head and neck squamous cell carcinoma (HNSCC) and squamous cervical cancer, EGFR amplifications were classified in Tier IIIA for these cancer types.

$B R A F$ V600E mutation are classified in Tier IA for melanoma patients treated with vemurafenib [20]. Based on these results and given the limited efficacy of vemurafenib in $B R A F$ V600E-mutated colorectal cancer patients [21, 22], BRAF V600E mutations were classified in Tier IIIA for colorectal cancer.

The predictive value of PDGFR, RET, LCK, and FLT3 alterations of PDGFR, RET, LCK, and FLT3 inhibitors' efficacy was only evaluated in preclinical models [14, 23-25]. These MAs were therefore classified in Tier IVA.

\section{Hormone receptor pathway}

Hormone therapy based on the expression of estrogen and/or progesterone receptors (ER/PR) is standard of care in breast cancer [26]. Since antitumor activity was only reported in ER/PR-positive ovarian cancer [27], these MAs were classified in Tier IIB for ovarian cancer, and in Tier IIIA in all other cancer types.

Androgen receptor (AR) are expressed in prostate cancer, explaining the high efficacy of abiraterone in this patient population [28]. Antitumor activity was reported in AR-positive breast cancer patients in a single-arm phase II trial [29]. AR expression was therefore classified in Tier IIB in breast cancer, and in Tier IIIA in all other cancer types.

\section{Efficacy of MTAs given in SHIVA01 according to ESCAT levels of evidence}

In total, out of the 153 patients treated with matched MTA in SHIVA01, 98 patients $(64 \%)$ had a Tier IIIA MA, 38 patients (25\%) a Tier II, seven patients (5\%) a Tier IIIB, and 10 
patients (7\%) a Tier IVA. No MAs were classified in Tier I because of the SHIVA01 design, and none in Tiers IVB and V.

Median PFS was 2 months [range: 0.5-18.2] in Tier II, 3.1 months [range: 0.4-18.0] in Tier IIIA, 1.7 months [range: 0.3-3.7] in Tier IIIB, and 3.1 months [range: 1.2-8.9] in Tier IVA $(\mathrm{p}=0.13)$ (Figure 1a). OS was worse in Tier IIIB than in Tiers II, IIIA and IVA (median OS of 6.3 months [range: 2.3-11.1] versus 11.7 months [range: 2.5-37.4], 11.2 months [range: 2.1-29.9], and 12.1 months [4.4-20.3], p=0.002) (Figure 1b).

\section{DISCUSSION}

Our study is, to our knowledge, the first study to retrospectively classify MAs used in a precision medicine trial according to ESCAT, and to reassess survival according to levels of actionability. Since ESCAT relies on published preclinical and clinical scientific data, the distribution in the different Tiers will certainly evolve with time.

Most MAs used to allocate therapy in SHIVA01 were MAs shown to improve outcome in other tumour types (ESCAT Tier IIIA). Worst outcome was observed in patients who were treated based on another type of alteration (example: amplifications versus activating mutations in oncogenes) in a specific gene than the one reported to improve outcome (ESCAT Tier IIIB). The functional impact of unvalidated MAs within actionable genes may be assessed using in vitro/vivo analyses [30]. Patients with MAs in Tier IVA had a longer OS than patients with MAs in Tier IIIB. Although the numbers are small, this result suggests that in silico functional analyses may be more informative than extrapolating potential functional impact of MAs relying on a same gene or pathway.

We encountered several limitations while classifying SHIVA01 MAs according to ESCAT. First, we noticed that the literature interpretation was subject to inter-individual variability. In an attempt to limit this variability, the classification was validated by several experts. Second, some MTAs considered as reference treatment in some indications were not 
assessed in randomized trials with a molecular selection based on the MA of interest, as was the case for KIT mutations and imatinib efficacy in GIST [31]. Other scales of actionability have overcome this limitation by classifying in Tier I FDA-approved drugs in a specific tumour type $[7,9,10]$. Third, there is no guidance in ESCAT on how to classify MAs associated with a lack of efficacy in specific tumour types. We classified BRAF V600E mutations in Tier IIIA for colorectal cancer based on melanoma data. However, given the limited efficacy of vemurafenib in colorectal cancer [21, 22], this MA may be rather classified in Tier V. Fourth, ESCAT doesn't take into account the impact of coexisting MAs that may confer resistance to therapy. As an example, PI3K inhibitors were shown to be effective in patients with tumours harbouring a PIK3CA mutation, while coexisting PIK3CA and KRAS mutations have been reported to predict limited efficacy of PI3K inhibitors [32].

Several parameters may impact the efficacy of MTAs beyond ESCAT level of actionability such MTA's affinity for a specific target. No recommendation exists on what should be the minimum affinity of a drug for a target to claim that a MA should be considered as a relevant target. The importance of MTA specificity is well illustrated by PIK3CA mutation and the use of alpelisib, an $\alpha$-specific PI3K inhibitor, classified in Tier IA in breast cancer based on the SOLAR-1 trial $[33,34]$ while the same mutation in the same tumour type is classified in Tier IIA for everolimus [13]. Despite the preclinical potency of sorafenib to inhibit RAF kinases [35], sorafenib did not demonstrate any efficacy in frequently $R A F$-mutated melanoma [36]. The efficacy of a drug can also be impacted by comedications or food that may influence pharmacokinetics, as well as an inappropriate dose reductions $[37,38]$.

\section{CONCLUSIONS}

The majority of MAs used in SHIVA01 to allocate therapy had a low level of actionability according to ESCAT. This might in part explain the negative result of SHIVA01. Taking into 
account other MAs in a specific gene than the one shown to improve outcome (Tier IIIB) was associated with worst outcome. This highlights the crucial importance of the type of alteration beyond the gene and/or the signaling pathway itself. Patients with MAs classified in Tier IVA had a better outcome than Tier IIIB, suggesting the value of in vitro and in vivo data for predicting MTA efficacy based on a specific MA.

\section{Conflict of interest :}

All authors of the manuscript declared no conflict of interest.

\section{Funding sources:}

This work was supported by the grant ANR-10-EQPX-03 from the Agence Nationale de le Recherche (Investissements d'avenir) and SiRIC (Site de Recherche Intégré contre le Cancer). High-throughput sequencing was performed by the NGS platform of the Institut Curie, supported by the grants ANR-10-EQPX-03 and ANR-10-INBS-09-08 from the Agence Nationale de le Recherche (investissements d'avenir) and by the Canceropôle Ile-deFrance. 


\section{References}

1. Chapman PB, Hauschild A, Robert $\mathrm{C}$ et al. Improved survival with vemurafenib in melanoma with BRAF V600E mutation. N. Engl. J. Med. 2011; 364(26):2507-2516.

2. Maemondo M, Inoue A, Kobayashi K et al. Gefitinib or chemotherapy for non-smallcell lung cancer with mutated EGFR. N. Engl. J. Med. 2010; 362(25):2380-2388.

3. Le Tourneau C, Delord J-P, Gonçalves A et al. Molecularly targeted therapy based on tumour molecular profiling versus conventional therapy for advanced cancer (SHIVA): a multicentre, open-label, proof-of-concept, randomised, controlled phase 2 trial. Lancet Oncol. 2015; 16(13):1324-1334.

4. André F, Bachelot T, Commo F et al. Comparative genomic hybridisation array and DNA sequencing to direct treatment of metastatic breast cancer: a multicentre, prospective trial (SAFIR01/UNICANCER). Lancet Oncol. 2014; 15(3):267-274.

5. Rodon J, Soria J-C, Berger R et al. Genomic and transcriptomic profiling expands precision cancer medicine: the WINTHER trial. Nat. Med. 2019; 25(5):751-758.

6. Le Tourneau C, Kamal M, Tsimberidou A-M et al. Treatment Algorithms Based on Tumor Molecular Profiling: The Essence of Precision Medicine Trials. J. Natl. Cancer Inst. 2016. doi:10.1093/jnci/djv362.

7. Chakravarty D, Gao J, Phillips SM et al. OncoKB: A Precision Oncology Knowledge Base. JCO Precis Oncol 2017. doi:10.1200/PO.17.00011.

8. Andre F, Mardis E, Salm M et al. Prioritizing targets for precision cancer medicine. Ann. Oncol. 2014; 25(12):2295-2303.

9. Li MM, Datto M, Duncavage EJ et al. Standards and Guidelines for the Interpretation and Reporting of Sequence Variants in Cancer: A Joint Consensus Recommendation of the Association for Molecular Pathology, American Society of Clinical Oncology, and College of American Pathologists. J Mol Diagn 2017; 19(1):4-23.

10. Meric-Bernstam F, Johnson A, Holla V et al. A decision support framework for 
genomically informed investigational cancer therapy. J. Natl. Cancer Inst. 2015. doi:10.1093/jnci/djv098.

11. Van Allen EM, Wagle N, Stojanov $\mathrm{P}$ et al. Whole-exome sequencing and clinical interpretation of formalin-fixed, paraffin-embedded tumor samples to guide precision cancer medicine. Nat. Med. 2014; 20(6):682-688.

12. Mateo J, Chakravarty D, Dienstmann $\mathrm{R}$ et al. A framework to rank genomic alterations as targets for cancer precision medicine: the ESMO Scale for Clinical Actionability of molecular Targets (ESCAT). Ann. Oncol. 2018; 29(9):1895-1902.

13. André F, Hurvitz S, Fasolo A et al. Molecular Alterations and Everolimus Efficacy in Human Epidermal Growth Factor Receptor 2-Overexpressing Metastatic Breast Cancers: Combined Exploratory Biomarker Analysis From BOLERO-1 and BOLERO-3. J. Clin. Oncol. 2016; 34(18):2115-2124.

14. Contreras CM, Akbay EA, Gallardo TD et al. Lkb1 inactivation is sufficient to drive endometrial cancers that are aggressive yet highly responsive to mTOR inhibitor monotherapy. Dis Model Mech 2010; 3(3-4):181-193.

15. Blackwell KL, Burstein HJ, Storniolo AM et al. Overall survival benefit with lapatinib in combination with trastuzumab for patients with human epidermal growth factor receptor 2-positive metastatic breast cancer: final results from the EGF104900 Study. J. Clin. Oncol. 2012; 30(21):2585-2592.

16. Demetri GD, von Mehren M, Blanke CD et al. Efficacy and safety of imatinib mesylate in advanced gastrointestinal stromal tumors. N. Engl. J. Med. 2002; 347(7):472480.

17. Heinrich MC, Corless CL, Demetri GD et al. Kinase mutations and imatinib response in patients with metastatic gastrointestinal stromal tumor. J. Clin. Oncol. 2003; 21(23):43424349.

18. Guo J, Si L, Kong Y et al. Phase II, open-label, single-arm trial of imatinib mesylate 
in patients with metastatic melanoma harboring c-Kit mutation or amplification. J. Clin. Oncol. 2011; 29(21):2904-2909.

19. Petty RD, Dahle-Smith A, Stevenson DAJ et al. Gefitinib and EGFR Gene Copy Number Aberrations in Esophageal Cancer. J. Clin. Oncol. 2017; 35(20):2279-2287.

20. Chapman PB, Robert C, Larkin $\mathrm{J}$ et al. Vemurafenib in patients with BRAFV600 mutation-positive metastatic melanoma: final overall survival results of the randomized BRIM-3 study. Ann. Oncol. 2017; 28(10):2581-2587.

21. Kopetz S, Desai J, Chan E et al. Phase II Pilot Study of Vemurafenib in Patients With Metastatic BRAF-Mutated Colorectal Cancer. J. Clin. Oncol. 2015; 33(34):4032-4038.

22. Hyman DM, Puzanov I, Subbiah V et al. Vemurafenib in Multiple Nonmelanoma Cancers with BRAF V600 Mutations. N. Engl. J. Med. 2015; 373(8):726-736.

23. Lierman E, Lahortiga I, Van Miegroet $\mathrm{H}$ et al. The ability of sorafenib to inhibit oncogenic PDGFRbeta and FLT3 mutants and overcome resistance to other small molecule inhibitors. Haematologica 2007; 92(1):27-34.

24. de Groot JWB, Plaza Menacho I, Schepers H et al. Cellular effects of imatinib on medullary thyroid cancer cells harboring multiple endocrine neoplasia Type 2A and 2B associated RET mutations. Surgery 2006; 139(6):806-814.

25. Laukkanen $\mathrm{S}$, Grönroos $\mathrm{T}$, Pölönen $\mathrm{P}$ et al. In silico and preclinical drug screening identifies dasatinib as a targeted therapy for T-ALL. Blood Cancer J 2017; 7(9):e604.

26. Rutqvist LE, Cedermark B, Fornander $\mathrm{T}$ et al. The relationship between hormone receptor content and the effect of adjuvant tamoxifen in operable breast cancer. J. Clin. Oncol. 1989; 7(10):1474-1484.

27. Bonaventura A, O’Connell RL, Mapagu C et al. Paragon (ANZGOG-0903): Phase 2 Study of Anastrozole in Women With Estrogen or Progesterone Receptor-Positive PlatinumResistant or -Refractory Recurrent Ovarian Cancer. Int. J. Gynecol. Cancer 2017; 27(5):900_ 906. 
28. Fizazi K, Tran N, Fein L et al. Abiraterone plus Prednisone in Metastatic, CastrationSensitive Prostate Cancer. N. Engl. J. Med. 2017; 377(4):352-360.

29. Bonnefoi $\mathrm{H}$, Grellety $\mathrm{T}$, Tredan $\mathrm{O}$ et al. A phase II trial of abiraterone acetate plus prednisone in patients with triple-negative androgen receptor positive locally advanced or metastatic breast cancer (UCBG 12-1). Ann. Oncol. 2016; 27(5):812-818.

30. Kamal M, Tarcic G, Dureau S et al. Revisited analysis of a SHIVA01 trial cohort using functional mutational analyses successfully predicted treatment outcome. Mol Oncol 2018; 12(5):594-601.

31. Heinrich MC, Griffith DJ, Druker BJ et al. Inhibition of c-kit receptor tyrosine kinase activity by STI 571, a selective tyrosine kinase inhibitor. Blood 2000; 96(3):925-932.

32. Di Nicolantonio F, Arena S, Tabernero J et al. Deregulation of the PI3K and KRAS signaling pathways in human cancer cells determines their response to everolimus. J. Clin. Invest. 2010; 120(8):2858-2866.

33. Condorelli R, Mosele F, Verret B et al. Genomic alterations in breast cancer: level of evidence for actionability according to ESMO Scale for Clinical Actionability of molecular Targets (ESCAT). Ann. Oncol. 2019; 30(3):365-373.

34. André F, Ciruelos E, Rubovszky G et al. Alpelisib for PIK3CA-Mutated, Hormone Receptor-Positive Advanced Breast Cancer. N. Engl. J. Med. 2019; 380(20):1929-1940.

35. Wilhelm SM, Adnane L, Newell $\mathrm{P}$ et al. Preclinical overview of sorafenib, a multikinase inhibitor that targets both Raf and VEGF and PDGF receptor tyrosine kinase signaling. Mol. Cancer Ther. 2008; 7(10):3129-3140.

36. Flaherty KT, Lee SJ, Zhao F et al. Phase III Trial of Carboplatin and Paclitaxel With or Without Sorafenib in Metastatic Melanoma. JCO 2013; 31(3):373-379.

37. Tannock IF, Hickman JA. Limits to Personalized Cancer Medicine. N. Engl. J. Med. 2016; 375(13):1289-1294.

38. Moreau-Bachelard C, Coquan E, Le Tourneau C. Imputability of Adverse Events to 
Anticancer Drugs. N. Engl. J. Med. 2019; 380(19):1873-1874. 
Figure 1. Kaplan-Meier estimates of (a) progression-free survival (PFS), and (b) overall survival (OS) of patients treated with matched molecularly targeted therapy in SHIVA01 according to ESCAT Tiers

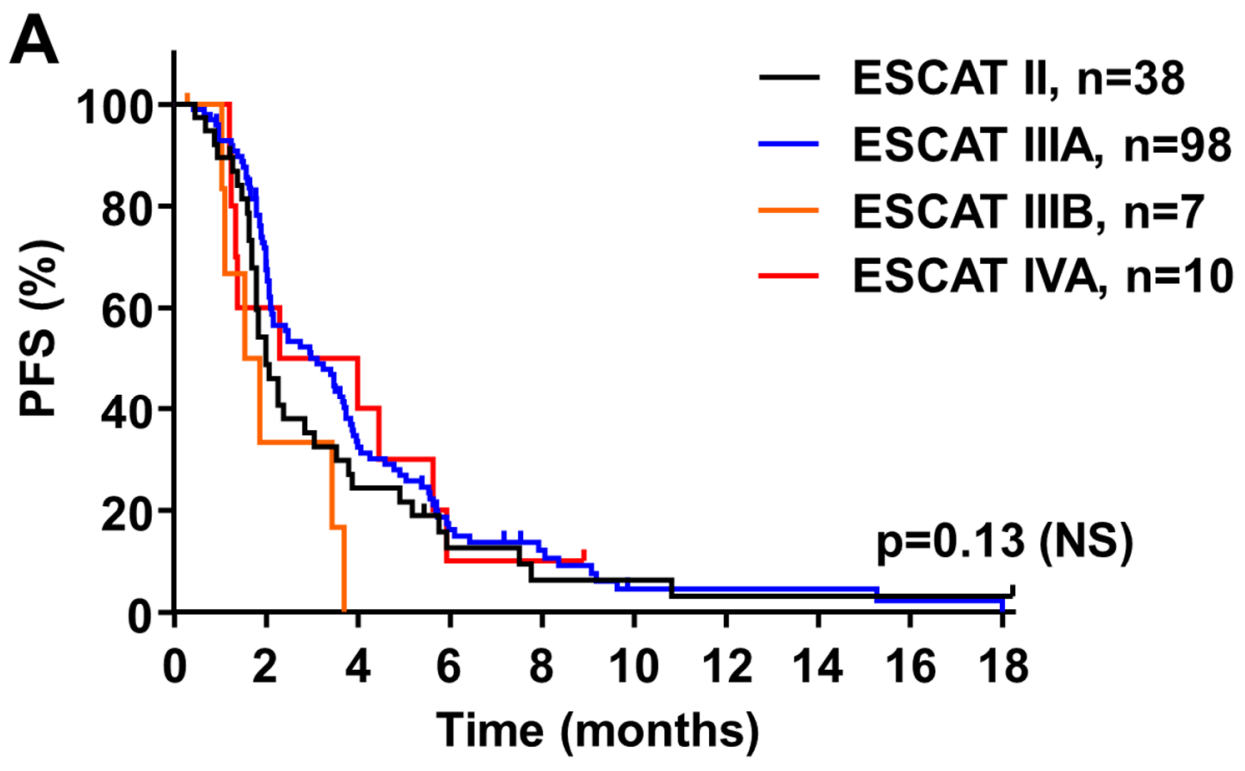

\section{B}

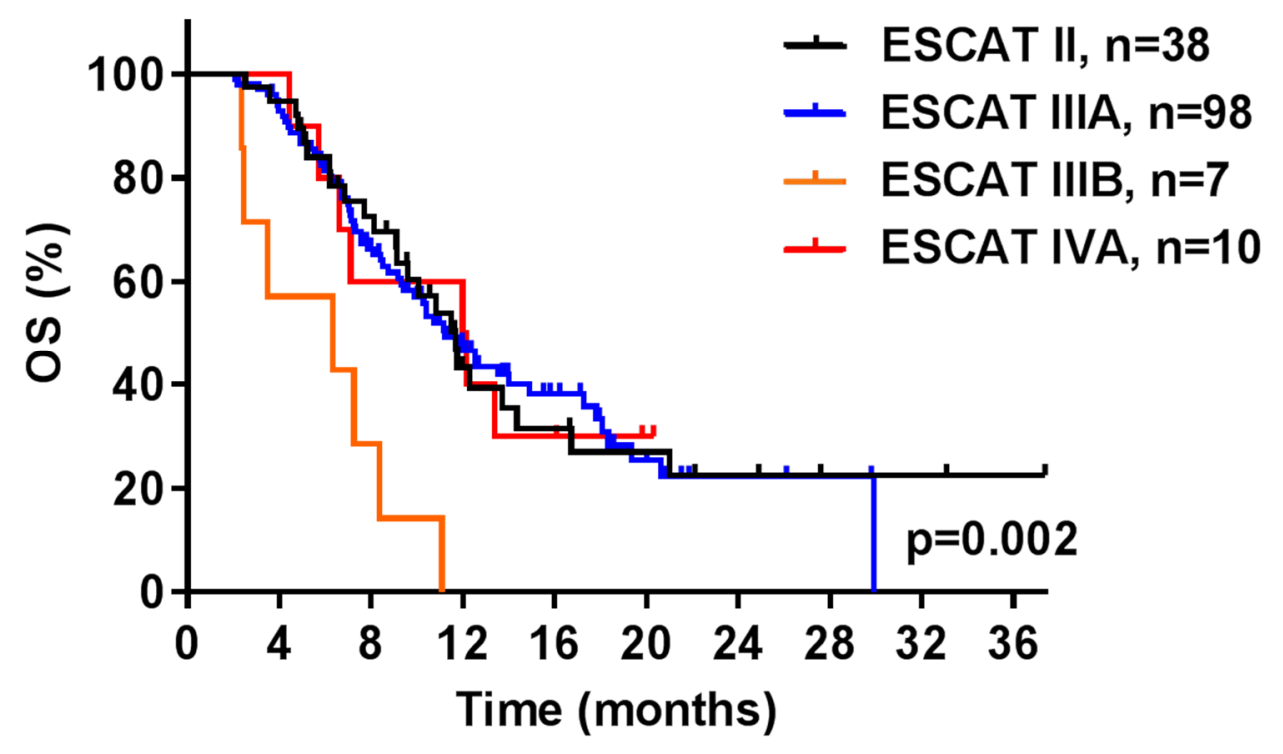


Table 1. Characteristics of patients treated with matched molecularly targeted therapy in SHIVA01

\begin{tabular}{|l|c|}
\hline & $\mathbf{N}(\%)$ \\
& (Total = 153) \\
\hline Gender & \\
Male & $52(34)$ \\
Female & $101(66)$ \\
\hline Tumour location & \\
PI3K/AKT/mTOR pathway & \\
Colorectal & $\mathbf{7 7 ( 5 0 )}$ \\
Breast & $14(9)$ \\
Ovarian & $12(8)$ \\
Lung & $10(7)$ \\
HNSCC & $8(5)$ \\
Endometrial & $6(4)$ \\
Cervical & $5(3)$ \\
Pancreatic & $5(3)$ \\
Sarcoma & $3(2)$ \\
Cholangiocarcinoma & $2(1)$ \\
Oesogastric & $2(1)$ \\
Anal & $2(1)$ \\
Melanoma & $1(1)$ \\
Adenoid cystic & $1(1)$ \\
Hepatocarcinoma & $1(1)$ \\
ACUP & $1(1)$ \\
Germline & $1(1)$ \\
Urothelial & $1(1)$ \\
Parotid & $1(1)$ \\
TKR/RAF/MEK pathway & $1(1)$ \\
Lung & $20(\mathbf{1 3})$ \\
Colorectal & $3(2)$ \\
Sarcoma & $3(2)$ \\
HNSCC & $2(1)$ \\
ACC & $2(1)$ \\
Neuroendocrine & $2(1)$ \\
Ovarian & $2(1)$ \\
Hepaticarcinoma & $1(1)$ \\
Melanoma & $1(1)$ \\
Oesogastric & $1(1)$ \\
Cervical & $1(1)$ \\
Urothelial & $1(1)$ \\
Hormone receptor pathway & $1(1)$ \\
Breast & $\mathbf{5 6}(\mathbf{3 7})$ \\
& $14(9)$ \\
& \\
\hline & \\
& \\
\hline
\end{tabular}




\begin{tabular}{|l|c} 
Ovarian & $14(9)$ \\
Lung & $4(3)$ \\
Sarcoma & $4(3)$ \\
Cervical & $3(2)$ \\
HNSCC & $2(1)$ \\
ACUP & $2(1)$ \\
Urothelial & $2(1)$ \\
Cavum & $2(1)$ \\
Oesogastric & $1(1)$ \\
Colorectal & $1(1)$ \\
Kidney & $1(1)$ \\
Endometrial & $1(1)$ \\
Hepatocarcinoma & $1(1)$ \\
Mixopapillary ependymoma & $1(1)$ \\
Pancreatic & $1(1)$ \\
Parotid & $1(1)$ \\
Uveal melanoma & $1(1)$
\end{tabular}

ACC = Adenoid Cystic Carcinoma; ACUP = Adenocarcinoma of Unknown Primary; $\mathrm{HCC}=$ Hepatocellular carcinoma; $\mathrm{HNSCC}=$ Head and Neck Squamous Cell Carcinoma 
Table 2. Classification of molecular alterations used in SHIVA01 to allocate molecularly targeted agents according to ESCAT

\begin{tabular}{|c|c|c|c|c|}
\hline Gene & Molecular alteration & Molecular targeted agent & Tumour type (N) & ESCAT Tier \\
\hline \multicolumn{5}{|c|}{ PI3K/AKT/mTOR pathway } \\
\hline \multirow{13}{*}{ PIKЗCA } & \multirow{13}{*}{ PIK3CA hotspot mutations } & \multirow{21}{*}{ Everolimus } & Breast (8) & IIA \\
\hline & & & Colorectal (5) & \multirow{12}{*}{ IIIA } \\
\hline & & & Endometrial (3) & \\
\hline & & & Cervical (2) & \\
\hline & & & Ovarian (2) & \\
\hline & & & Oesogastric (1) & \\
\hline & & & Pancreatic (1) & \\
\hline & & & Cholangiocarcinoma (1) & \\
\hline & & & HNSCC (1) & \\
\hline & & & $\mathrm{ACC}(1)$ & \\
\hline & & & Anal (1) & \\
\hline & & & Lung (1) & \\
\hline & & & Cervical (1) & \\
\hline \multirow{8}{*}{ PTEN } & \multirow{8}{*}{$P T E N$ inactivation } & & Breast (4) & IIA \\
\hline & & & Colorectal (9) & \multirow{7}{*}{ IIIA } \\
\hline & & & Ovarian (7) & \\
\hline & & & Lung (5) & \\
\hline & & & HNSCC (4) & \\
\hline & & & Pancreatic (2) & \\
\hline & & & Sarcoma (2) & \\
\hline & & & ACUP (1) & \\
\hline
\end{tabular}




\begin{tabular}{|c|c|c|c|c|}
\hline \multirow{9}{*}{ PTEN } & \multirow{9}{*}{ PTEN inactivation } & \multirow{15}{*}{ Everolimus } & Cervical (1) & \\
\hline & & & Parotid (1) & \\
\hline & & & $\mathrm{HCC}(1)$ & \\
\hline & & & Oesogastric (1) & \\
\hline & & & Melanoma (1) & \\
\hline & & & Germline (1) & \\
\hline & & & Endometrial (1) & \\
\hline & & & Cholangiocarcinoma (1) & \\
\hline & & & Urothelial (1) & \\
\hline \multirow{5}{*}{$A K T$} & \multirow{2}{*}{ AKT1 amplification } & & HNSCC (1) & \multirow{3}{*}{ IIIB } \\
\hline & & & Lung (1) & \\
\hline & AKT2 amplification & & Ovarian (1) & \\
\hline & \multirow{2}{*}{ AKT1 E17K mutation } & & Endometrial (1) & \multirow{2}{*}{ IIIA } \\
\hline & & & Cervical (1) & \\
\hline STK11 & D194L mutation + LOH & & Lung (1) & IVA \\
\hline \multicolumn{5}{|c|}{ TKR/RAF/MEK pathway } \\
\hline \multirow{4}{*}{$E R B B 2$} & \multirow{2}{*}{ Amplification } & \multirow{4}{*}{ Lapatinib and trastuzumab } & Lung (1) & \multirow{2}{*}{ IIIA } \\
\hline & & & Urothelial (1) & \\
\hline & S792F mutation & & Colorectal (1) & $I I I R$ \\
\hline & T862A mutation & & Neuroendocrine Anal (1) & 1110 \\
\hline \multirow{4}{*}{$K I T$} & D572G mutation (Exon 11) & \multirow{4}{*}{ Imatinib } & Lung (1) & IIIA \\
\hline & P838S mutation (Exon 18) & & Melanoma (1) & IIB \\
\hline & V852I mutation (Exon 18) & & Ovarian (1) & \multirow{2}{*}{ IIIB } \\
\hline & M722V mutation (Exon 15) & & $\mathrm{HCC}(1)$ & \\
\hline \multirow{2}{*}{$E G F R$} & \multirow{2}{*}{ EGFR amplification } & \multirow{2}{*}{ Erlotinib } & HNSCC (1) & \multirow{2}{*}{ IIIA } \\
\hline & & & Cervical (1) & \\
\hline
\end{tabular}




\begin{tabular}{|c|c|c|c|c|}
\hline$B R A F$ & V600E mutation & Vemurafenib & Colorectal (1) & IIIA \\
\hline \multirow{5}{*}{$P D G F R A / B$} & \multirow{2}{*}{ PDGFRA amplification } & \multirow{5}{*}{ Sorafenib } & $\mathrm{ACC}(2)$ & \multirow{5}{*}{ IVA } \\
\hline & & & Sarcoma (1) & \\
\hline & PDGFRB amplification & & Colorectal (1) & \\
\hline & $P D G F R A$ activation (intragenic deletion) & & Sarcoma (1) & \\
\hline & PDGFRA L655Y mutation & & HNSCC (1) & \\
\hline FLT3 & M665T mutation & Sorafenib & Lung (1) & IVA \\
\hline$R E T$ & Amplification & Imatinib & Oesogastric (1) & IVA \\
\hline$L C K$ & Amplification & Dasatinib & Neuroendocrine (1) & IVA \\
\hline \multicolumn{5}{|l|}{ HR pathway } \\
\hline \multirow{9}{*}{\multicolumn{2}{|c|}{ ER-PR }} & \multirow{9}{*}{ Tamoxifen } & Ovarian (11) & IIB \\
\hline & & & Cervical (3) & \multirow{8}{*}{ IIIA } \\
\hline & & & Sarcoma (2) & \\
\hline & & & Lung (2) & \\
\hline & & & HNSCC (2) & \\
\hline & & & Urothelial (1) & \\
\hline & & & Cavum (1) & \\
\hline & & & Colorectal (1) & \\
\hline & & & Oesogastric (1) & \\
\hline \multirow{6}{*}{\multicolumn{2}{|c|}{ AR }} & \multirow{6}{*}{ Abiraterone } & Breast (14) & IIB \\
\hline & & & Ovarian (3) & \multirow{5}{*}{ IIIA } \\
\hline & & & Sarcoma (2) & \\
\hline & & & Lung (2) & \\
\hline & & & ACUP (2) & \\
\hline & & & $\mathrm{HCC}(1)$ & \\
\hline
\end{tabular}




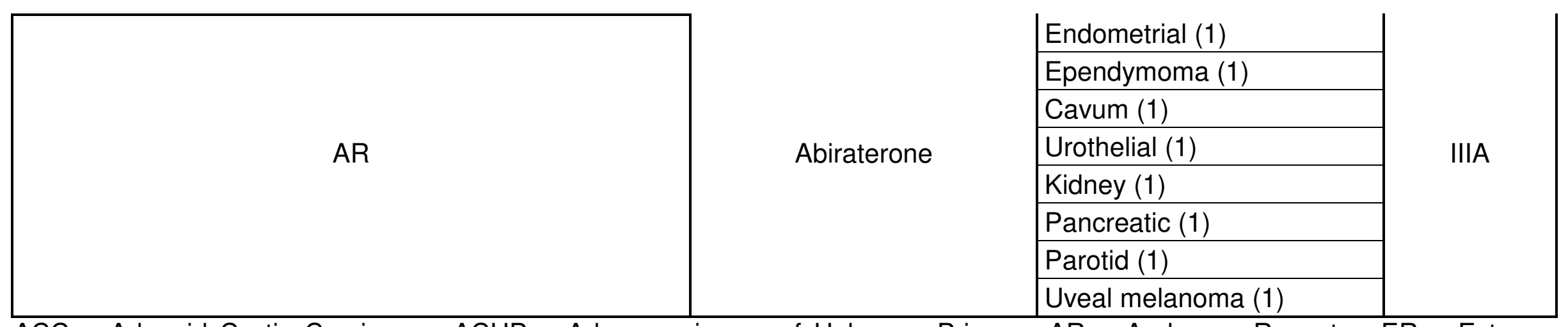

ACC = Adenoid Cystic Carcinoma; ACUP = Adenocarcinoma of Unknown Primary; AR = Androgen Receptor; ER = Estrogen Receptor; HCC = Hepatocellular Carcinoma; HNSCC = Head and Neck Squamous Cell Carcinoma; LOH = Loss Of Heterozygosity; $\mathrm{PR}=$ Progesterone Receptor

PTEN inactivation = homozygous deletion of PTEN, or LOH associated with an inactivating mutation of PTEN, or LOH with loss of PTEN expression in immunohistochemistry, in all cases validated using immunohistochemistry

PDGFRA activation = intragenic deletion within PDGFRA validated by overexpression of PGDFRA using immunohistochemistry 